\title{
PENGARUH PENGGUNAAN METODE PEMBELAJARAN SMALL GROUP WORK DAN MEDIA AUDIO VISUAL POWERPOINT TERHADAP HASIL BELAJAR KOGNITIF SISWA PADA MATA PELAJARAN AL-QUR'AN HADITS
}

\author{
Eka Abdul Hamid \\ Program Studi Agama Islam \\ Sekolah Tinggi Agama Islam (STAI) Sebelas April Sumedang \\ Jl. Angkrek Situ No. 19, Sumedang, 45323 Indonesia \\ Email: ekahamid23@gmail.com
}

\begin{abstract}
Abstrak
Menurut dugaan peneliti, terdapat dua faktor yang sangat menentukan keberhasilan dalam kegiatan pembelajaran. Kedua faktor tersebut: 1) faktor media yang digunakan, karena dalam kenyataannya tidak ketersediaan media yang sesuai dengan zaman modern seperti infokus, infokus memudahkan guru dalam menyampaikan materi dan tentunya akan berdampak positif bagi peserta didik meningkatkan hasil belajar kognitif mereka. 2) faktor metode penyampaian, karena dalam kenyataannya peserta didik tidak memperhatikan akan penyampaian materi karena penggunaan metode dalam pembelajaran kurang bervariatif yang hanya mengandalkan metode ceramah. Tujuan dari penelitian ini untuk Mengetahui perbedaan Hasil Belajar Kognitif Siswa antara yang menggunakan pembelajaran Konvensional dengan Metode Small Group Work dan Media Audio Visual PowerPoint. Metode penelitian yang digunakan dalam penelitian ini adalah metode Quasi Eksperimen. Desain penelitiannya digunakan Nonequivalen Control Group Design. Untuk melihat perbedaan hasil belajar kognitif siswa digunakan Uji t pada data pretest dan posttest. Dari hasil penelitian menunjukkan hasil belajar kognitif siswa sebelum diberikan perlakuan dikelas eksperimen rata-rata 42,87 dan kelas kontrol rata-rata 41,56. Dan setelah diberikan perlakuan dikelas eksperimen rata-rata 83 dan kelas kontrol rata-rata 70,25. Disimpulkan bahwa terdapat perbedaan hasil belajar kognitif siswa antara kelas kontrol dan kelas eksperimen. Berdasarkan kesimpulan tersebut, penggunaan metode small group work dan media audio visual powerpoint dapat digunakan sebagai alternatif pembelajaran yang mampu meningkatkan hasil belajar kognitif siswa.
\end{abstract}

Kata Kunci : small group work, Power Point, Hasil belajar kognitif

\begin{abstract}
According to alleged researchers, there are two factors that determine the success of learning activities. These two factors: 1) media factors used, because in reality the availability of media that is suitable with modern times such as infokus, infokus makes it easier for teachers to deliver material and certainly will have a positive impact on students improving their cognitive learning outcomes. 2) delivery method factors, because in reality students do not pay attention to the delivery of material because the use of methods in learning is less varied which only relies on the lecture method. The purpose of this study is to find out the differences between students' cognitive learning outcomes using conventional learning with the small group work method and audio visual media media. The research method used in this study was the Quasi Experiment method. The research design used Nonequivalent Control Group Design. To see the differences in student cognitive learning outcomes used t test on pretest and posttest data. From the results of the study showed the
\end{abstract}


cognitive learning outcomes of students before being given treatment in the experimental class averaged 42.87 and the average control class 41.56 . And after being given treatment in the experimental class an average of 83 and the control class averaged 70.25. It was concluded that there were differences in cognitive learning outcomes of students between the control class and the experimental class. Based on these conclusions, the use of the small group work method and audio visual powerpoint media can be used as alternative learning that can improve students' cognitive learning outcomes.

Keywords: small group work, Power Point, cognitive learning outcomes

\section{PENDAHULUAN}

Upaya mencerdaskan kehidupan bangsa dan mengembangkan kualitas manusia seutuhnya merupakan misi pendidikan yang menjadi tanggung jawab profesional seorang guru. Pengembangan kualitas manusia ini menjadi suatu keharusan dalam pencapaian tujuan pendidikan. Pendidikan yang berorientasi pada kualitas ini menghadapi berbagai tantangan yang tidak dapat ditanggulangi dengan paradigma lama.

Salah satu refleksi dari pencapaian tujuan pendidikan itu proses belajar mengajar. Proses belajar mengajar merupakan proses kegiatan interaksi antara dua unsur manusiawi, yakni peserta didik sebagai pihak yang belajar dan guru sebagai pihak yang mengajar, dengan peserta didik sebagai subjek pokonya. ${ }^{1}$ Tujuan proses belajar secara ideal agar bahan yang dipelajari dapat dikuasai sepenuhnya oleh peserta didik. Pengajaran dapat dikatakan berjalan dengan baik dan berhasil bila guru mampu menumbuhkembangkan kesadaran peserta didik untuk belajar, sehingga pengalaman yang diperoleh siswa selama proses belajar mengajar dapat dirasakan perubahannya.

Keberhasilan pencapaian tujuan pendidikan tergantung kepada keberhasilan proses belajar yang dialami peserta didik. Belajar merupakan suatu proses usaha yang dilakukan seseorang untuk memperoleh suatu perubahan yang baru, sebagai hasil pengalamannya sendiri dalam interaksi dengan lingkungannya. ${ }^{2}$ Berdasarkan definisi tersebut, belajar pada hakikatnya perubahan yang terjadi di dalam diri seseorang setelah melakukan aktivitas belajar. Belajar yang terpenting proses bukan hasil yang diperolehnya. Belajar harus diperoleh dengan usaha sendiri, sedangkan orang lain itu hanya sebagai perantara atau penunjang dalam kegiatan belajar.

Salah satu hal yang dapat dilakukan guru dalam upaya meningkatkan hasil belajar kognitif peserta didik adalah menambah keterampilan mengajarnya dan memiliki kreatifitaskreatifitas dalam menerapkan metode pembelajaran serta menggunakan media pembelajaran.

\footnotetext{
${ }^{1}$ Sardiman, A.M, Interaksi dan Motivasi Belajar Mengajar (Jakarta: Raja Grafindo Persada, 2014), 14.

${ }^{2}$ M. Sobry Sutikno, Belajar dan Pembelajaran (Bandung: Prospect, 2008), 4.
} 
Media pembelajaran yang tepat dan didukung dengan keterampilan guru diharapkan dapat meningkatkan prestasi belajar peserta didik. Seorang guru harus dapat mengikuti perkembangan teknologi informasi dan komunikasi serta dapat memilih metode dan memanfaatkan suatu media pembelajaran baik media berbasis visual, audio, dan audio visual. Salah satu yang dapat meningkatkan motivasi belajar siswa dalam mata pelajaran al-Qur'an Hadits itu penggunaan metode Small Group Work dan media audio visual PowerPoint.

Metode pembelajaran merupakan suatu usaha yang dilakukan oleh para pelaksana kurikulum agar proses belajar mengajar terselenggara sesuai dengan tujuan yang ingin dicapai, salah satunya menggunakan metode Small Group Work. Metode pembelajaran dikatakan relevan jika mampu mengantarkan peserta didik mencapai tujuan pendidikan pada umumnya dan tujuan pembelajaran PAI khususnya yang diharapkan dapat terlaksana melalui pengajaran.

Pendekatan kelompok dapat ditumbuhkembangkan rasa sosial yang tinggi dalam diri setiap peserta didik. Small Group Work salah satu metode pembelajaran yang dibina untuk mengendalikan rasa egois di antara peserta didik sehingga terbina sikap kesetiakawanan sosial di kelas. Peserta didik dibiasakan hidup bersama, bekerja sama kelompok, akan menyadari bahwa dirinya memiliki kekurangan dan kelebihan. Persaingan positif pun terjadi di kelas dalam rangka untuk mencapai tujuan pembelajaran yang optimal.

Selain metode, media juga merupakan salah satu komponen yang dapat mempermudah penyampaian materi dan dapat meningkatkan hasil belajar kognitif siswa. Salah satu media yang dapat mempermudah penyampaian materi itu media PowerPoint. Microsoft PowerPoint merupakan program aplikasi presentasi dalam komputer. Sebagai program aplikasi presentasi yang populer, Microsoft PowerPoint paling banyak digunakan untuk berbagai kepentingan presentasi, baik presentasi produk, meeting, seminar, lokakarya, dan pembelajaran. ${ }^{3}$ Salah satu keunggulan media PowerPoint dalam pembelajaran: 1) mampu menampilkan objek-objek yang sebenarnya tidak ada secara fisik atau diistilahkan dengan imagery. Pembelajaran dengan menggunakan mental imagery secara kognitif akan meningkatkan retensi peserta didik dalam mengingat materi-materi pelajaran. 2) dapat mengakomodasi peserta didik sesuai dengan modalitas belajarnya terutama bagi mereka yang memiliki tipe visual, auditif, kinestetik, atau yang lainnya. ${ }^{4}$

Berdasarkan hasil studi pendahuluan yang telah dilakukan di MTs S Rohmatul Ummah Narimbang Sumedang khususnya dalam proses pembelajaran al-Qur'an Hadits kelas

\footnotetext{
${ }^{3}$ Susilana, Rudi dan Cepi Riyana, Media Pembelajaran (Bandung: CV Wacana Prima, 2007), 99.

${ }^{4}$ Yudhi Munadi, Media Pembelajaran (Jakarta: GP Press, 2008), 150.
} 
VIII A dan VIII B diperoleh bahwa hasil belajar kognitif peserta didik dalam materi tentang hukum bacaan qalqalah, Tafkhim, dan Mad Arid lis-Sukun menunjukkan hasil yang kurang memuaskan. Hal ini dapat dilihat dari nilai yang diperoleh dari tes harian $38 \%$ peserta didik kelas VIII A yang nilainya kurang dari KKM yang diterapkan dalam Mata Pelajaran alQur'an Hadits yaitu 79. Begitu pula peserta didik kelas VIII B 47\% nilainya belum mencapai KKM. Hasil belajar peserta didik yang rendah dalam materi hukum bacaan qalqalah, Tafkhim, dan Mad Arid lis-Sukun karena peserta didik sulit memahami materi yang diajarkan. Ketika proses pembelajaran ada sebagian peserta didik yang tidak memperhatikan penjelasan guru, mengobrol dengan teman sebangkunya, metode yang digunakan kurang menarik perhatian peserta didik. Sehingga peserta didik kurang aktif mengemukakan pendapat dan masih banyak peserta didik yang pasif dibandingkan dengan yang aktif.

Hasil belajar kognitif peserta didik secara teoretis seharusnya harus terus meningkat seiring kemajuan zaman dan teknologi, dan tentunya perlu digunakan berbagai kreativitas guru dalam menyampaikan pembelajaran, sehingga pembelajaran tidak monoton. Masalah tersebut, tentu saja, dipengaruhi oleh banyak faktor. Diantaranya faktor media penggunaan dan metode dalam penyampaian kepada peserta didik, menurut dugaan peneliti, terdapat dua faktor yang sangat menentukan. Kedua faktor tersebut: 1) faktor media yang digunakan, karena dalam kenyataannya tidak ketersediaan media yang sesuai dengan zaman modern seperti infokus, infokus memudahkan guru dalam menyampaikan materi dan tentunya akan berdampak positif bagi peserta didik meningkatkan hasil belajar kognitif mereka. 2) faktor metode penyampaian, karena dalam kenyataannya peserta didik tidak memperhatikan akan penyampaian materi karena penggunaan metode dalam pembelajaran kurang bervariatif yang hanya mengandalkan metode ceramah.

Sesuai dengan latar belakang masalah di atas, maka dapat diidentifikasi bahwa masalah penelitian ini "Pengaruh Penggunaan Metode Pembelajaran Small Group Work dan Media Audio Visual PowerPoint terhadap Hasil Belajar Kognitif Siswa pada Mata Pelajaran Al-Qur'an Hadits (Penelitian eksperimen di kelas VIII MTs S Rohmatul Ummah Narimbang Kabupaten Sumedang).

\section{PEMBAHASAN}

Metode yang digunakan penulis dalam penelitian ini adalah metode quasi eksperimen. Quasi eksperimen adalah suatu bentuk eksperimen yang ciri utama validasinya tidak dilakukan secara random, melainkan menggunakan kelompok yang sudah ada namun memiliki karakteristik yang homogen dimaksudkan untuk memudahkan pengontrolan 
variabel penelitian. Desain ini mempunyai kelompok kontrol, tetapi tidak dapat berfungsi sepenuhnya untuk mengkontrol variabel-variabel luar yang mempengaruhi pelaksanaan eksperimen. ${ }^{5}$ Metode ini digunakan dengan maksud untuk mengetahui perbedaan hasil belajar kognitif siswa dengan perlakuan yang berbeda. Penggunaan metode quasi eksperimen ini didasarkan atas pertimbangan agar dalam pelaksanaan penelitian siswa tidak merasa sedang diteliti dalam proses pembelajaran berjalan secara wajar, sehingga dengan situasi yang demikian diharapkan dapat memberikan kontribusi terhadap tingkat kevalidan penelitian.

Penelitian ini dimaksudkan untuk mengetahui suatu perlakuan, maka terdapat variabel-variabel penelitian. Ada dua variabel dalam penelitian ini dengan desain sebagai berikut:

Tabel 1

Desain Penelitian

\begin{tabular}{|c|c|c|c|}
\hline $\begin{array}{c}\text { Kelompok } \\
\text { (Group) }\end{array}$ & $\begin{array}{c}\text { Test Awal } \\
\text { (Pre-test) }\end{array}$ & $\begin{array}{c}\text { Perlakuan } \\
\text { (Treatment) }\end{array}$ & $\begin{array}{c}\text { Test Akhir } \\
\text { (Post-test) }\end{array}$ \\
\hline$K E_{1}$ & $O_{1}$ & $X_{1}$ & $O_{2}$ \\
\hline$K E_{2}$ & $O_{3}$ & $X_{2}$ & $O_{4}$ \\
\hline Efek Perlakuan : $\left(O_{2}-O_{1}\right)-\left(O_{4}-O_{3}\right)$ \\
\hline
\end{tabular}

Keterangan: ${ }^{6}$

$K E_{1}=$ Pembelajaran kelas Eksperimen

$K E_{2}=$ Pembelajaran kelas Kontrol

$X_{1}=$ Pembelajaran dengan menggunakan metode small group work dan media audio visual powerpoint

$X_{2}=$ Pembalajaran dengan menggunakan metode konvensional

$O_{1}=$ Hasil belajar sebelum diberi perlakuan

$\mathrm{O}_{2}=$ Hasil belajar setelah diberi perlakuan

$\mathrm{O}_{3}=$ Hasil belajar sebelum diberi perlakuan

$\mathrm{O}_{4}=$ Hasil belajar setelah diberi perlakuan

Maka pengaruh perlakuannya adalah : $(\mathrm{O} 2-\mathrm{O} 1)-(\mathrm{O} 4-\mathrm{O} 3)^{7}$

${ }^{5}$ Sugiyono, Metode Penelitian Kuantitatif, Kualitatif, dan Kombinasi.(Bandung: Alfabeta, 2015), 116.

${ }^{6}$ Sugiyono. Statistik Untuk Penelitian. (Bandung: Alfabeta, 2012), 116.

${ }^{7}$ Sugiyono, Metode Penelitian, 118. 


\section{Prosedur dan Teknik Pemeriksaan Uji Keabsahan Data}

Alat pengumpul data tertulis dalam penelitian ini ialah tes. Tes terdiri dari 20 soal pilihan ganda dengan bobot skor 5 .

Untuk memastikan validitas dan reliabilitasnya, maka dilakukan pengujian sebagai berikut:

\section{Uji Validitas}

Validitas alat ukur menentukan sejauh mana alat ukur penelitian mampu mengukur variabel yang terdapat dalam suatu penelitian, atau dengan kata lain bahwa validitas merupakan suatu ukuran yang menunjukkan tingkat akurasi suatu alat ukur.

Suatu alat ukur atau skala pengukuran dikatakan valid jika skala pengukuran mengukur apa yang dimaksud untuk diukur; atau alat ukur yang salah atau tidak tepat akan mempunyai validitas yang rendah, begitu juga sebaliknya. Pengujian validitas alat ukur dalam penelitian ini menggunakan pendekatan korelasi point biserial, dengan rumus: ${ }^{8}$

$\mathrm{rpbi}=\frac{M p-M t}{S D t} \sqrt{\frac{p}{q}}$

Dalam hal ini:

rpbi $=$ Koefisien korelasi point biserial (koefisien validitas item)

$\mathrm{Mp}=$ Skor rata-rata yang dimiliki test untuk butir soal yang dijawab dengan benar

$\mathrm{Mt}=$ Skor rata-rata dari skor total

$\mathrm{SDt}=$ Standar deviasi dari skor total

$\mathrm{p}=$ Proporsi test yang menjawab benar terhadap butir soal yang sedang diuji validitas itemnya

$\mathrm{q}=$ Proporsi test yang menjawab salah terhadap butir soal yang sedang diuji validitas itemnya

Dengan ketentuan Jika rpbi $\geq \mathrm{r}$ tabel, maka soal tersebut dinyatakan valid dan dapat dipakai, dan Jika rpbi < r tabel, maka soal tersebut dinyatakan invalid dan perlu melakukan penelitian pada tahap selanjutnya.

\footnotetext{
${ }^{8}$ Subana, dkk. Statistik Pendidikan, (Bandung: Pustaka Setia, 2000), 156.
} 
Tabel 2

Interpretasi Validitas Tes

\begin{tabular}{|c|c|c|c|c|l|l|l|l|}
\hline $\begin{array}{c}\text { No } \\
\text { Soal }\end{array}$ & $\mathrm{Mp}$ & $\mathrm{Mt}$ & $\mathrm{SDt}$ & $\mathrm{p}$ & $\mathrm{Q}$ & $\mathrm{rpbi}=\frac{M p-M t}{S D t} \sqrt{\frac{p}{q}}$ & $\mathrm{r} \%$ tabel & Interpretasi \\
\hline 1 & 12,9 & 12,7 & 2,86 & 0,9 & 0,1 & 0,207 & 0,325 & Invalid \\
\hline 2 & 14,6 & 12,7 & 2,86 & 0,35 & 0,65 & 0,481 & 0,325 & Valid \\
\hline 3 & 14,2 & 12,7 & 2,86 & 0,6 & 0,4 & 0,641 & 0,325 & Valid \\
\hline 4 & 13,4 & 12,7 & 2,86 & 0,85 & 0,15 & 0,580 & 0,325 & Valid \\
\hline 5 & 13,7 & 12,7 & 2,86 & 0,55 & 0,45 & 0,385 & 0,325 & Valid \\
\hline 6 & 13,8 & 12,7 & 2,86 & 0,5 & 0,5 & 0,384 & 0,325 & Valid \\
\hline 7 & 12,1 & 12,7 & 2,86 & 0,35 & 0,65 & $-0,099$ & 0,325 & Invalid \\
\hline 8 & 14,1 & 12,7 & 2,86 & 0,45 & 0,55 & 0,442 & 0,325 & Valid \\
\hline 9 & 8,4 & 12,7 & 2,86 & 0,55 & 0,45 & $-1,66$ & 0,325 & Invalid \\
\hline 10 & 12,9 & 12,7 & 2,86 & 0,95 & 0,05 & 0,3 & 0,325 & Invalid \\
\hline 11 & 12,7 & 12,7 & 2,86 & 1 & 0 & 0 & 0,325 & Invalid \\
\hline 12 & 12,8 & 12,7 & 2,86 & 0,9 & 0,1 & 0,102 & 0,325 & Invalid \\
\hline 13 & 12,9 & 12,7 & 2,86 & 0,85 & 0,15 & 0,164 & 0,325 & Invalid \\
\hline 14 & 13,4 & 12,7 & 2,86 & 0,6 & 0,4 & 0,298 & 0,325 & Invalid \\
\hline 15 & 12,9 & 12,7 & 2,86 & 0,6 & 0,4 & 0,084 & 0,325 & Invalid \\
\hline 16 & 13,3 & 12,7 & 2,86 & 0,8 & 0,2 & 0,418 & 0,325 & Valid \\
\hline 17 & 15,4 & 12,7 & 2,86 & 0,3 & 0,7 & 0,617 & 0,325 & Valid \\
\hline 18 & 12,9 & 12,7 & 2,86 & 0,75 & 0,25 & 0,119 & 0,325 & Invalid \\
\hline 19 & 13,7 & 12,7 & 2,86 & 0,45 & 0,55 & 0,315 & 0,325 & Invalid \\
\hline 20 & 12,6 & 12,7 & 2,86 & 0,45 & 0,55 & $-0,030$ & 0,325 & Invalid \\
\hline
\end{tabular}

Dari hasil uji coba instrumen penelitian untuk variabel hasil belajar kognitif diperoleh kesimpulan bahwa dari 20 item tersebut 8 item valid dan 12 item invalid

2. Uji Reliabilitas

Reliabel berasal dari bahasa Inggris "reliable" artinya ajeg atau dapat dipercaya. Suatu tes dapat dikatakan memiliki taraf kepercayaan atau daya keajegan yang tinggi apabila tes tersebut kapan pun dujikan dapat memberikan hasil yang sama kepada siswa yang sama. Untuk menguji reliabilitas alat ukur, terlebih dahulu dicari harga korelasi secara keseluruhan dengan menggunakan formula Kuder Richardson. Adapun tahapan yaitu: ${ }^{9}$

1) Menyiapkan tabel perhitungan

2) Menentukan jumlah deviasi total kuadrat dengan rumus: ${ }^{10}$

$$
\begin{aligned}
\sum X t^{2} & =\sum X t^{2}-\frac{\left(\sum X t\right)^{2}}{N} \\
& =6287-\frac{471^{2}}{37} \\
& =6287-\frac{221841}{37} \\
& =6287-5995 \\
& =\mathbf{2 9 2}
\end{aligned}
$$

${ }^{9}$ Tuti Hayati. Modul Evaluasi Pembelajaran PAI, (Bandung: Fakultas Tarbiyah UIN, 2012), 26.

10 Tuti Hayati. Modul Evaluasi Pembelajaran PAI, 27. 
3) Menentukan varian total $\left(S^{2} t\right)$ dengan rumus: ${ }^{11}$

$S^{2} t=\frac{\sum X t^{2}}{N}=\frac{292}{37}=7,89$

4) Menentukan koefisien reliabilitas $\left(r_{11}\right)$ dengan rumus: ${ }^{12}$

$$
\begin{aligned}
& \boldsymbol{r}_{\mathbf{1 1}}=\left(\frac{\boldsymbol{n}}{\boldsymbol{n - 1}}\right)\left(\frac{\boldsymbol{S}_{-}{ }_{-} \text {Spiqi }}{\boldsymbol{S}^{2} \boldsymbol{t}}\right) \\
& \mathrm{r}_{11}=\left(\frac{20}{20-1}\right)\left(\frac{7,89-3,62}{7,89}\right) \\
& \mathrm{r}_{11}=\left(\frac{20}{19}\right)\left(\frac{4,27}{7,89}\right) \\
& \mathrm{r}_{11}=(1,052)(0,541) \\
& \mathbf{r}_{\mathbf{1 1}}=\mathbf{0}, \mathbf{5 6 9}
\end{aligned}
$$

5) Menginterpretasikan koefisien reliabilitas tes dengan ketentuan: ${ }^{13}$

$\sim$ Jika $\mathbf{r}_{11} \geq \mathbf{0 , 7 0}$, maka tes tersebut reliabel; dan

$\sim$ Jika $\mathbf{r}_{\mathbf{1 1}}<\mathbf{0 , 7 0}$, maka tes tersebut tidak reliabel

Instrumen penelitian uji coba soal dinyatakan tidak reliabel, karena $\mathbf{r}_{11}=\mathbf{0 , 5 6 9}<$ $\mathbf{0 , 7 0}$

\section{Daya Pembeda}

Analisis daya pembeda mengkaji butir-butir soal dengan tujuan untuk megetahui kesanggupan soal dalam membedakan siswa yang tergolong mampu (tinggi prestasinya) dengan siswa yang tergolong kurang atau lemah prestasinya. Artinya, bila soal tersebut diberikan kepada anak yang mampu, hasilnya menunjukkan prestasi yang tinggi. Sementara jika diberikan kepada siswa yang lemah hasilnya rendah. Tes dikatakan tidak memiliki daya pembeda apabila tes tersebut jika diujikan kepada siswa yang berprestasi hasilnya rendah, tetapi bila diterapkan kepada siswa yang lemah hasilnya tinggi.

${ }^{11}$ Tuti Hayati. Modul Evaluasi Pembelajaran PAI, 28.

12 Tuti Hayati. Modul Evaluasi Pembelajaran PAI, 28.

${ }^{13}$ Tuti Hayati. Modul Evaluasi Pembelajaran PAI, 28. 
Adapun rumus unutk mengetahui indeks daya pembeda yaitu: ${ }^{14}$

$\mathrm{DP}=\frac{S A-S B}{\frac{1}{2} n \cdot M a k s}$

Keterangan:

SA = Jumlah Skor yang dicapai kelompok atas

$\mathrm{SB}=$ jumlah Skor yang dicapai kelompok bawah

$\mathrm{n}=$ Jumlah siswa keseluruhan

Maks $=$ Skor Maksimal soal (Pokok Uji)

Dengan kriteria daya pembeda sebagai berikut: ${ }^{15}$

Tabel 3

Klasifikasi Daya Pembeda

\begin{tabular}{|c|c|}
\hline Nilai DP & Kriteria \\
\hline $0,40-$ ke atas & Baik \\
\hline $0,21-0,39$ & Kurang \\
\hline $0,20-$ ke bawah & Jelek \\
\hline
\end{tabular}

4. Tingkat Kesukaran

Asumsi yang digunakan untuk memperoleh kualitas soal yang baik disamping memenuhi validitas dan reliabilitas, adanya keseimbangan dari tingkat kesulitan soal tersebut. Keseimbangan yang dimaksud adalah adanya soal-soal yang mudah, sedang, dan sulit secara proporsional.

Cara melakukan analisis untuk menentukan tingkat kesukaran soal adalah dengan menggunakan rumus sebagai berikut: ${ }^{16}$

$\mathrm{TK}=\frac{S A+S B}{\frac{1}{2} n \cdot M a k s}$

Keterangan:

$\mathrm{SA}=$ Jumlah Skor yang dicapai kelompok atas

SB = Jumlah Skor yang dipakai kelompok bawah

$\mathrm{n}=$ Jumlah siswa kelompok atas dan kelompok bawah

Maks $=$ Skor Maksimal soal $($ pokok uji)

Dengan klasifikasi Tingkat Kesukaran sebagai berikut: ${ }^{17}$

Tabel 4

Klasifikasi Tingkat Kesukaran

\begin{tabular}{|c|c|}
\hline Nilai TK & Kriteria \\
\hline 0,29 - ke bawah & Sukar \\
\hline
\end{tabular}

${ }^{14}$ Tuti Hayati. Modul Evaluasi Pembelajaran PAI, 35.

${ }^{15}$ Tuti Hayati. Modul Evaluasi Pembelajaran PAI, 35.

16 Tuti Hayati. Modul Evaluasi Pembelajaran PAI, 35.

17 Tuti Hayati. Modul Evaluasi Pembelajaran PAI, 35. 


\begin{tabular}{|c|c|}
\hline $0,30-0,69$ & Sedang \\
\hline $0,70-$ ke atas & Mudah \\
\hline
\end{tabular}

Dari perhitungan daya pembeda dan tingkat kesukaran dengan menggunakan bantuan microsoft excel, maka diperoleh sebagai berikut:

Tabel 5

Format Perhitungan Daya Pembeda dan Tingkat Kesukaran Soal

\begin{tabular}{|c|c|c|c|c|c|c|c|c|c|c|c|c|c|}
\hline \multirow[b]{2}{*}{$\begin{array}{l}\text { No } \\
\text { Soal }\end{array}$} & \multirow[b]{2}{*}{ BA } & \multirow[b]{2}{*}{$\mathrm{BB}$} & \multirow[b]{2}{*}{$\mathrm{BA}+\mathrm{BB}$} & \multirow[b]{2}{*}{ BA-BB } & \multirow[b]{2}{*}{$\mathrm{N}$} & \multicolumn{4}{|c|}{$\begin{array}{c}\text { Daya } \\
\text { Pembeda } \\
\text { (DP) }\end{array}$} & \multicolumn{4}{|c|}{$\begin{array}{c}\text { Tingkat } \\
\text { Kesukaran } \\
(\text { TK) }\end{array}$} \\
\hline & & & & & & $\begin{array}{c}\text { Inde } \\
\text { ks }\end{array}$ & $\begin{array}{l}\mathrm{B} \\
\mathrm{a} \\
\mathrm{i} \\
\mathrm{k}\end{array}$ & $\begin{array}{l}\mathrm{K} \\
\mathrm{u} \\
\mathrm{r} \\
\mathrm{a} \\
\mathrm{n} \\
\mathrm{g}\end{array}$ & $\begin{array}{l}\mathrm{J} \\
\mathrm{e} \\
\mathrm{l} \\
\mathrm{e} \\
\mathrm{k}\end{array}$ & $\begin{array}{c}\text { Ang } \\
\text { ka }\end{array}$ & $\begin{array}{l}\mathrm{M} \\
\mathrm{u} \\
\mathrm{d} \\
\mathrm{a} \\
\mathrm{h}\end{array}$ & $\begin{array}{l}\mathrm{S} \\
\mathrm{e} \\
\mathrm{d} \\
\mathrm{a} \\
\mathrm{n} \\
\mathrm{g}\end{array}$ & $\begin{array}{l}\mathrm{S} \\
\mathrm{u} \\
\mathrm{k} \\
\mathrm{a} \\
\mathrm{r}\end{array}$ \\
\hline 1 & 17 & 16 & 33 & 1 & 36 & 0,05 & & & $\sqrt{ }$ & 0,91 & $\sqrt{1}$ & & \\
\hline 2 & 12 & 2 & 14 & 10 & 36 & 0,55 & $\sqrt{ }$ & & & 0,38 & & $\sqrt{ }$ & \\
\hline 3 & 16 & 5 & 21 & 11 & 36 & 0,61 & $\sqrt{ }$ & & & 0,58 & & $\sqrt{ }$ & \\
\hline 4 & 18 & 12 & 30 & 6 & 36 & 0,33 & & $\sqrt{1}$ & & 0,83 & $\sqrt{ }$ & & \\
\hline 5 & 13 & 8 & 21 & 5 & 36 & 0,27 & & $\sqrt{6}$ & & 0,58 & & $\sqrt{ }$ & \\
\hline 6 & 10 & 7 & 17 & 3 & 36 & 0,16 & & & $\sqrt{1}$ & 0,47 & & $\sqrt{ }$ & \\
\hline 7 & 8 & 4 & 12 & 4 & 36 & 0,22 & & $\sqrt{6}$ & & 0,33 & & $\sqrt{ }$ & \\
\hline 8 & 11 & 5 & 16 & 6 & 36 & 0,33 & & $\sqrt{ }$ & & 0,44 & & $\sqrt{ }$ & \\
\hline 9 & 12 & 8 & 20 & 4 & 36 & 0,22 & & $\sqrt{ }$ & & 0,55 & & $\sqrt{ }$ & \\
\hline 10 & 18 & 16 & 34 & 2 & 36 & 0,11 & & & $\sqrt{1}$ & 0,94 & $\sqrt{ }$ & & \\
\hline 11 & 18 & 18 & 36 & 0 & 36 & 0 & & & $\sqrt{1}$ & 1 & $\sqrt{1}$ & & \\
\hline 12 & 18 & 15 & 33 & 3 & 36 & 0,16 & & & $\sqrt{1}$ & 0,91 & $\sqrt{1}$ & & \\
\hline 13 & 16 & 14 & 30 & 2 & 36 & 0,11 & & & $\sqrt{1}$ & 0,83 & $\sqrt{1}$ & & \\
\hline 14 & 13 & 9 & 22 & 4 & 36 & 0,22 & & $\sqrt{1}$ & & 0,61 & & $\sqrt{ }$ & \\
\hline 15 & 11 & 11 & 22 & 0 & 36 & 0 & & & $\sqrt{1}$ & 0,61 & & $\sqrt{ }$ & \\
\hline 16 & 17 & 11 & 28 & 6 & 36 & 0,33 & & $\sqrt{1}$ & & 0,77 & $\sqrt{1}$ & & \\
\hline 17 & 11 & 1 & 12 & 10 & 36 & 0,55 & $\sqrt{ }$ & & & 0,33 & & $\sqrt{ }$ & \\
\hline 18 & 15 & 12 & 27 & 3 & 36 & 0,16 & & & $\sqrt{ }$ & 0,75 & $\sqrt{1}$ & & \\
\hline 19 & 11 & 5 & 16 & 6 & 36 & 0,33 & & $\sqrt{ }$ & & 0,44 & & $\sqrt{ }$ & \\
\hline 20 & 8 & 8 & 16 & 0 & 36 & 0 & & & $\sqrt{ }$ & 0,44 & & $\sqrt{ }$ & \\
\hline
\end{tabular}

Keterangan:

DP = Daya Pembeda

TK = Tingkat Kesukaran

BA = Jumlah jawaban benar kelompok atas

$\mathrm{BB}=$ Jumlah jawaban benar kelompok bawah

$\mathrm{n} \quad=$ Jumlah kelompok atas dan kelompok bawah

Pada tabel 3.6 di atas dapat dilihat bahwa daya pembeda yang terdiri dari 20 butir soal, terdapat tiga butir soal berdaya bedanya baik, delapan butir soal yang memiliki daya pembedanya kurang, dan sembilan butir soal yang memiliki daya beda jelek. Pada uji tingkat 
kesukaran soal terdapat delapan butir soal yang berkategori mudah, dua belas butir soal yang berkategori sedang, sedangkan yang berkategori sukar tidak ada.

Dari ketiga analisis soal tersebut bisa diinterpretasikan kedalam tabel sebagai berikut:

Tabel 6

Interpretasi Uji Coba Soal

\begin{tabular}{|c|c|c|c|c|c|}
\hline \multirow{2}{*}{$\begin{array}{l}\text { No } \\
\text { Soal }\end{array}$} & \multicolumn{3}{|c|}{ Interpretasi } & \multirow[b]{2}{*}{ Keterangan } & \multirow[b]{2}{*}{ Soal Dipaka } \\
\hline & Validitas & $\begin{array}{c}\text { Tingkat } \\
\text { Kesukaran }\end{array}$ & $\begin{array}{c}\text { Daya } \\
\text { Pembeda }\end{array}$ & & \\
\hline 1 & Invalid & Mudah & Jelek & Revisi & - \\
\hline 2 & Valid & Sedang & Baik & Dipakai & 1 \\
\hline 3 & Valid & Sedang & Baik & Dipakai & 2 \\
\hline 4 & Valid & Mudah & Kurang & Dipakai & 3 \\
\hline 5 & Valid & Sedang & Kurang & Dipakai & 4 \\
\hline 6 & Valid & Sedang & Jelek & Dipakai & 5 \\
\hline 7 & Invalid & Sedang & Kurang & Dipakai & 6 \\
\hline 8 & Valid & Sedang & Kurang & Dipakai & 7 \\
\hline 9 & Invalid & Sedang & Kurang & Dipakai & 8 \\
\hline 10 & Invalid & Mudah & Jelek & Revisi & - \\
\hline 11 & Invalid & Mudah & Jelek & Revisi & - \\
\hline 12 & Invalid & Mudah & Jelek & Revisi & - \\
\hline 13 & Invalid & Mudah & Jelek & Revisi & - \\
\hline 14 & Invalid & Sedang & Kurang & Dipakai & 9 \\
\hline 15 & Invalid & Sedang & Jelek & Dipakai & 10 \\
\hline 16 & Valid & Mudah & Kurang & Dipakai & 11 \\
\hline 17 & Valid & Sedang & Baik & Dipakai & 12 \\
\hline 18 & Invalid & Mudah & Jelek & Dipakai & 13 \\
\hline 19 & Invalid & Sedang & Kurang & Dipakai & 14 \\
\hline 20 & Invalid & Sedang & Jelek & Dipakai & 15 \\
\hline
\end{tabular}

Dari tabel diatas, dapat dilihat ada 5 item butir soal yang direvisi yaitu nomor 1, 10, 11, 12 dan 13 sedangkan sisanya dipakai.

\section{Prosedur Analisis Data}

Variabel dalam penelitian ini ada 3, yaitu metode pembelajaran small group work sebagai variabel pertama (independent variabel, dengan notasi statistik $\mathrm{X}_{1}$ ) dan media audio 
visual PowerPoint sebagai variabel bebas kedua (independent variabel, dengan notasi statistik $\mathrm{X}_{2}$ ), sedangkan Hasil Belajar Kognitif Siswa sebagai variabel terikat (dependent variabel, dengan notasi statistik Y).

Paradigma penelitian menjelaskan bagaimana penelitian memahami suatu masalah, serta kriteria pengujian sebagai landasan untuk menjawab masalah penelitian. Paradigma penelitian ini adalah:

Gambar 1

Paradigma Penelitian

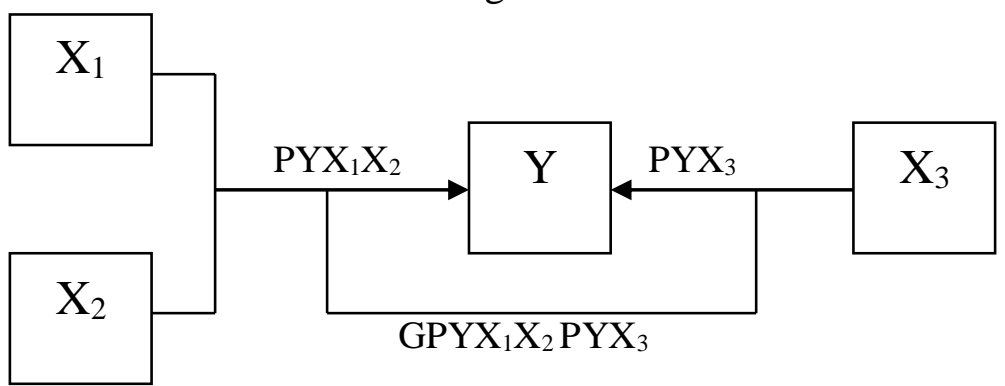

Keterangan:

$\mathrm{X}_{1}$

: Penggunaan metode pembelajaran small group work

$\mathrm{X}_{2}$

: Penggunaan media audio visual powerpoint

$\mathrm{X}_{3}$

: Penggunaan metode konvensional

Y

: Hasil belajar kognitif siswa pada mata pelajaran qur'an hadits

$\mathrm{PYX}_{1} \mathrm{X}_{2} \quad$ : Pengaruh penggunaan metode pembelajaran small group work dan media audio visual powerpoint terhadap hasil belajar kognitif siswa pada mata pelajaran qur'an hadits

$\mathrm{PYX}_{3} \quad:$ Pengaruh penggunaan metode pembelajaran konvensional terhadap hasil belajar kognitif siswa

$\mathrm{GPYX}_{1} \mathrm{X}_{2} \mathrm{PYX}_{3}$ : Perbedaan hasil belajar kognitif siswa antara yang menggunakan metode pembelajaran konvensional dengan yang menggunakan metode pembelajaran small group work dan media audio visual powerpoint

Sesuai dengan paradigma tersebut, maka hipotesis yang diuji dalam penelitian pengaruh penggunaan metode pembelajaran small group work dan media audio visual powerpoint terhadap hasil belajar kognitif siswa adalah sebagai berikut:

1. $\mathrm{H}_{0} \quad$ : Tidak terdapat pengaruh yang positif dan signifikan dari metode pembelajaran konvensional terhadap hasil belajar kognitif siswa. 
$\mathrm{H}_{\mathrm{a}} \quad$ : Terdapat pengaruh yang positif dan signifikan dari metode pembelajaran konvensional terhadap hasil belajar kognitif siswa.

2. $\mathrm{H}_{0}$ : Tidak terdapat pengaruh yang positif dan signifikan dari metode pembelajaran small group work dan media audio visual powerpoint terhadap hasil belajar kognitif siswa.

$\mathrm{H}_{\mathrm{a}} \quad$ : Terdapat pengaruh yang positif dan signifikan dari metode pembelajaran small group work dan media audio visual powerpoint terhadap hasil belajar kognitif siswa.

3. $\mathrm{H}_{0}$ : Tidak terdapat perbedaan hasil belajar kognitif siswa antara yang menggunakan metode pembelajaran konvensional dengan metode pembelajaran small group work dan media audio visual powerpoint.

$\mathrm{H}_{\mathrm{a}} \quad$ : Terdapat perbedaan hasil belajar kognitif siswa antara yang menggunakan metode pembelajaran konvensional dengan metode pembelajaran small group work dan media audio visual powerpoint.

Semua data hasil penyebaran tes ini diberi skor dan dianalisis dengan menggunakan uji statistik. Teknik analisis data yang digunakan dalam penelitian adalah teknik pretest, posttes, dan gain, yaitu pretest digunakan untuk menguji persamaan kedua kelas tersebut dari hasil belajar kognitif mereka. Posttest digunakan untuk menentukan perbedaan kedua kelas tersebut yang diberikan perlakuan yang berbeda. Gain digunakan untuk menentukan perbedaan antara kedua perlakuan tersebut.

Adapun analisisnya akan dilakukan melalui dua pendekatan, yaitu analisis parsial dan analisis banding. Sistematika penganalisisan dari pendekatan tersebut secara rinci dapat dilakukan dengan langkah-langkah sebagai berikut:

1. Analisis Parsial

Analisis parsial yaitu analisis yang dilakukan untuk mendalami kedua variabel. Dalam hal ini untuk mengetahui variabel $X_{1}$ dan $X_{2}$. Untuk mendalami kedua variabel tersebut langkah-langkah yang dilakukan adalah sebagai berikut:

\section{a. Uji Normalitas Data}

Uji normalitas digunakan untuk mengetahui apakah populasi data berdistribusi normal atau tidak. Uji ini biasanya digunakan untuk mengukur data berskala ordinal, interval, ataupun rasio. Jika analisis menggunakan metode parametrik, maka persyaratan normalitas harus terpenuhi yaitu data berasal dari distribusi yang normal. Jika data tidak berdistribusi normal, atau jumlah sampel sedikit dan jenis data adalah nominal atau ordinal maka metode 
yang digunakan adalah statistik non parametrik. Dalam pembahasan ini alat ujinya menggunakan rumus chi kuadrat $\left(X^{2}\right)$ harga yang diperlukan untuk uji normalitas data pretest dan posttest kelas eksperimen dan kelas kontrol dengan menggunakan taraf signifikansi 0,05 . Data dinyatakan berdistribusi normal jika signifikansi lebih besar dari 5\% atau 0,05.

Setelah dilakukan pengolahan data dengan perhitungan statistik untuk lebih meyakinkan dugaan bahwa distribusi frekuensi normal alat ujinya menggunakan rumus chi kuadrat $\left(X^{2}\right)$ harga yang diperlukan untuk uji normalitas data pretest dan posttest kelas eksperimen dan kontrol dapat dilihat pada tabel dibawah ini :

Tabel 7

Deskripsi Hasil Belajar Kelas Eksperimen dan Kelas Kontrol

\begin{tabular}{|l|c|c|c|c|}
\hline \multirow{2}{*}{\multicolumn{1}{|c|}{ Parameter }} & \multicolumn{2}{c|}{ Eksperimen } & \multicolumn{2}{c|}{ Kontrol } \\
\cline { 2 - 5 } & Pretest & Posttest & Pretest & Posttest \\
\hline Skor Tertinggi & 55 & 95 & 55 & 85 \\
\hline Skor Terendah & 25 & 70 & 25 & 55 \\
\hline Jumlah Responden & 16 & 16 & 16 & 16 \\
\hline Kelas Interval & 5 & 5 & 5 & 5 \\
\hline Panjang Kelas & 7 & 6 & 7 & 7 \\
\hline Rata-rata (Mean) & 42,87 & 83 & 41,56 & 70,25 \\
\hline Standar Deviasi (Sd) & 9,85 & 8,33 & 8,27 & 10,38 \\
\hline $\begin{array}{l}\text { Chi Kuadrat Hitung } \\
\left(X_{\text {hitung }}^{2}\right)\end{array}$ & 2,1505 & 4,8481 & 4,5919 & 3,6973 \\
\hline Chi Kuadrat Tabel $\left(X_{\text {tabel }}^{2}\right)$ & 5,99 & 5,99 & 5,99 & 5,99 \\
\hline Derajat Kebebasan $(d k)$ & 2 & 2 & 2 & 2 \\
\hline
\end{tabular}

Dari tabel di atas berikut rumus-rumus yang dipakai oleh peneliti:

a. Mencari Nilai Rentang (R)

$\mathrm{R}=($ Data tertinggi - Data terendah $)$

b. Menentukan Banyaknya Kelas Interval (K)

$\mathrm{K}=1+3,3(\log \mathrm{n})$

c. Menentukan Panjang Kelas Interval (P)

$\mathrm{P}=\frac{R}{K}$

d. Membuat Tabel Distribusi Frekuensi

e. Menentukan Nilai Mean $(\bar{X})$

$\bar{X}=\frac{\sum f i \quad x i}{\sum f i}$

f. Menentukan Standar Deviasi (Sd) 
$\mathrm{Sd}=\sqrt{\frac{\sum f_{i} x_{i}{ }^{2}-\frac{\left(\Sigma f_{i} x_{i}\right)^{2}}{\sum f_{i}}}{\sum f_{i}{ }^{-1}}}$

g. Membuat daftar distribusi frekuensi observasi dan ekspektasi

h. Menghitung nilai Chi Kuadrat

$$
X^{2}=\sum_{i-1}^{k} \frac{(O i-E i)^{2}}{E i}
$$

i. Menentukan Derajat Kebebasan (dk)

$\mathrm{dk}=\mathrm{Ki}-3$

j. Menentukan $X^{2}$ tabel dengan taraf signifikansi 5\%

Uji normalitas digunakan untuk mengetahui suatu data berdistribusi normal atau tidak. Suatu data dikatakan normal apabila memenuhi kriteria jika $X_{\text {hitung }}^{2}<X_{\text {tabel }}^{2}$, maka data berdistribusi normal. Tetapi apabila $X_{\text {hitung }}^{2}>X_{\text {tabel }}^{2}$ maka data berdistribusi tidak normal. Dari hasil analisis data pretest kelas eksperimen menunjukkan bahwa $X_{\text {hitung }}^{2}=$ $2,1505<5,99=X_{\text {tabel }}^{2}$ maka data hasil tes berdistribusi Normal dan data pretest kelas kontrol menunjukkan bahwa $X_{\text {hitung }}^{2}=4,5919<5,99=X_{\text {tabel }}^{2}$ maka data hasil tes berdistribusi Normal, sedangkan untuk data posttest kelas eksperimen menunjukkan bahwa $X_{\text {hitung }}^{2}=4,8481<5,99=X_{\text {tabel }}^{2}$ maka data hasil tes berdistribusi Normal dan data posttest kelas kontrol menunjukkan bahwa $X_{\text {hitung }}^{2}=3,6973<5,99=X_{\text {tabel }}^{2}$ maka data hasil tes berdistribusi Normal.

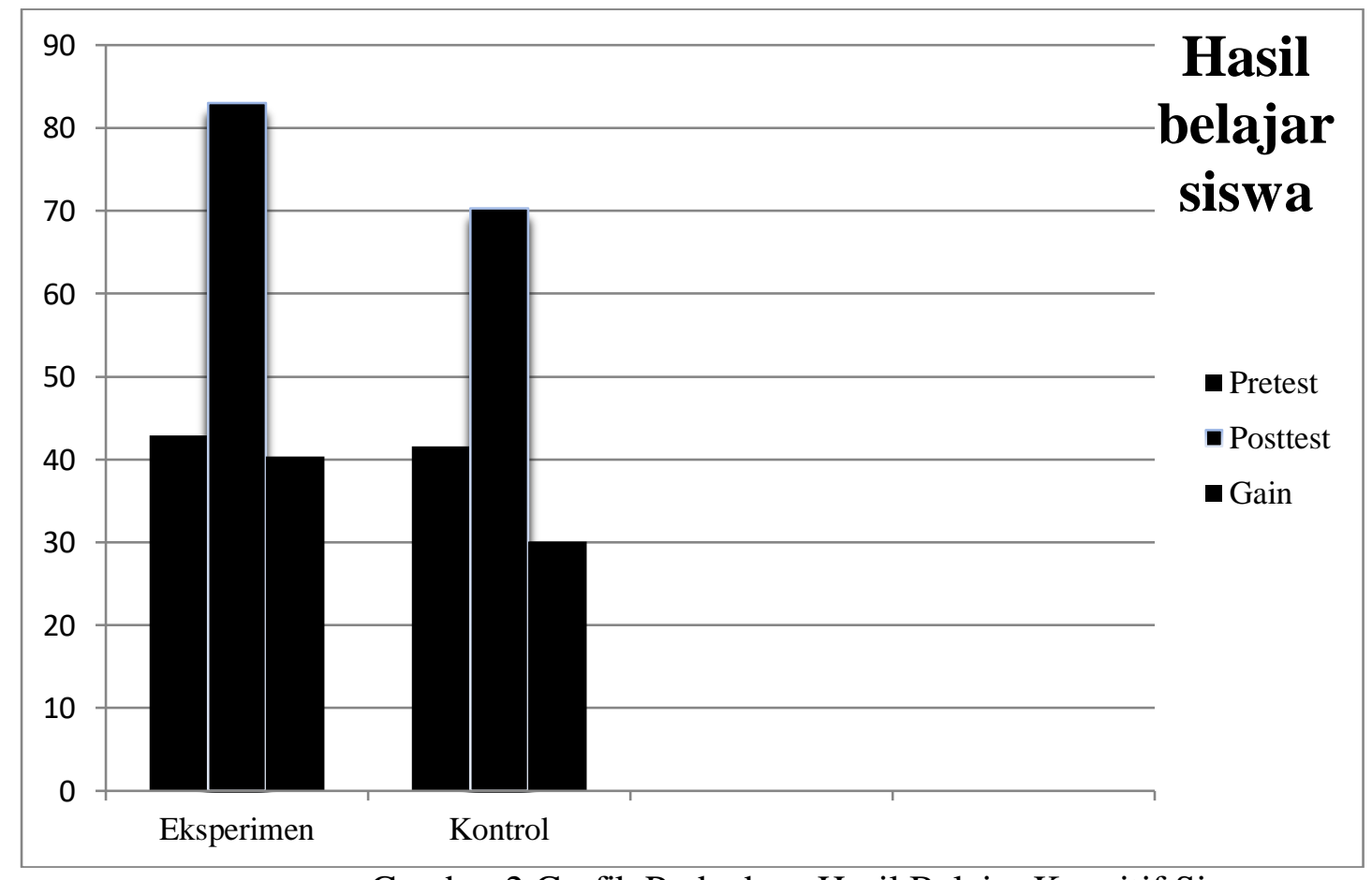

2. Analisis Banding

Gambar 2 Grafik Perbedaan Hasil Belajar Kognitif Siswa 
Dalam analisis banding ini menempuh langkah-langkah sebagai berikut:

b. Tes Homogenitas dua variabel

Uji homogenitas digunakan untuk mengetahui apakah beberapa varian populasi adalah sama atau tidak. Uji ini dilakukan sebagai prasyarat dalam analisis independent sample $t$ test dan ANOVA. Asumsi yang mendasari dalam analisis varian (ANOVA) adalah bahwa varian dari populasi adalah sama. Sebagai kriteria pengujian, jika nilai signifikansi lebih dari 0,05 maka dapat dikatakan bahwa varian dari dua atau lebih kelompok data adalah sama. Adapun rumus yang digunakan adalah: 
a) Menentukan nilai $\mathrm{F}$ dengan rumus ${ }^{18}$

$\mathrm{F}=\frac{V_{b}}{V_{k}}$

Ket:

$\mathrm{Vb}=$ Varians Besar

$\mathrm{Vk}=$ Varians Kecil

b) Menentukan derajat kebebasan dengan rumus:

$\mathrm{dk}=n_{1}-1 \quad \mathrm{dk}=n_{2}-1$

c) Menentukan nilai F dari daftar, dengan taraf signifikansi $5 \%$

d) Menentukan homogenitas dengan cara membandingkan harga $\mathrm{F}$ hitung dengan $\mathrm{F}$ daftar dengan kriteria sebagai berikut:

i. Jika F hitung < F tabel, maka variasi homogen.

ii. Jika $\mathrm{F}$ hitung $>\mathrm{F}$ tabel, maka variabel tidak homogen.

Tabel 8

Nilai Variansi $\left(s d^{2}\right)$

\begin{tabular}{|c|c|c|c|c|}
\hline \multirow{2}{*}{ Parameter } & \multicolumn{2}{|c|}{ Eksperimen } & \multicolumn{2}{c|}{ Kontrol } \\
\cline { 2 - 5 } & Pretest & Posttest & Pretest & Posttest \\
\hline$s d$ & 9,85 & 8,33 & 8,27 & 10,38 \\
\hline$s d^{2}$ & 97,02 & 69,3 & 68,39 & 107,7 \\
\hline
\end{tabular}

Dilihat dari tabel di atas menentukan nilai $s d^{2}$ (variansi) menunjukkan data Pretest kelas eksperimen tidak jauh berbeda dari nilai Pretest kelas kontrol, sedangkan Posttest kelas eksperimen lebih kecil dari nilai Posttest kelas kontrol.

Tabel 9

Hasil Perhitungan Uji Homogenitas

\begin{tabular}{|c|c|c|c|}
\hline Nilai yang dicari & Fhitung & Ftabel & Keterangan \\
\hline Pretest & 1,418 & 2,41 & Homogen \\
\hline Posttest & 1,55 & 2,41 & Homogen \\
\hline
\end{tabular}

Dilihat dari tabel di atas menunjukkan kedua data Pretest dan Posttest kelas eksperimen dan kelas kontrol homogen.

c. Uji T Tes (Hipotesis)

Uji Hipotesis adalah cabang Ilmu Statistika Inferensial yang dipergunakan untuk menguji kebenaran suatu pernyataan secara statistik dan menarik kesimpulan apakah menerima atau menolak pernyataan tersebut. Pernyataan ataupun asumsi sementara yang dibuat untuk diuji kebenarannya tersebut dinamakan dengan Hipotesis (Hypothesis) atau Hipotesa. Tujuan dari Uji Hipotesis adalah untuk menetapkan suatu dasar sehingga dapat mengumpulkan bukti yang berupa data-data dalam menentukan keputusan apakah menolak atau menerima kebenaran dari pernyataan atau asumsi yang telah dibuat. Uji Hipotesis juga

${ }^{18}$ Subana, dkk. Statistik Pendidikan, 171. 
dapat memberikan kepercayaan diri dalam pengambilan keputusan yang bersifat Objektif. Adapun rumus yang dipakai dalam pengujian hipotesis sebagai berikut:

a) Mencari nilai deviasi standar gabungan (dsg) dengan menggunakan rumus: ${ }^{19}$

$$
d s g=\sqrt{\frac{\left(n_{1}-1\right) V 1+\left(n_{2}-1\right) V 2}{n_{1}+n_{2}-2}}
$$

Ket:

$n_{1}=$ banyaknya data kelompok 1

$n_{2}=$ banyaknya data kelompok 2

$v_{1}=$ varians data kelompok 1

$v_{2}=$ varians data kelompok 2

b) Menentukan $t$ hitung dengan rumus: ${ }^{20}$

$$
t=\frac{\overline{X_{1}}-\overline{X_{2}}}{\sqrt[d s g]{\frac{1}{n_{1}}+\frac{1}{n_{2}}}}
$$

Ket:

$\overline{X_{1}}=$ rata-rata data kelompok 1

$\overline{X_{2}}=$ rata-rata data kelompok 2

$d s g=$ nilai deviasi standar gabungan

c) Menghitung derajat kebebasan (db), untuk mencari harga kritik " $t$ " dengan rumus $:^{21}$

$\mathrm{db}=\left(n_{1}+n_{2}-2\right)$

d) Menentukan nilai t tabel dari daftar dengan taraf signifikan 5\%

e) Menentukan alternative hipotesis dengan ketentuan :

i. Jika $t_{\text {hitung }}>t_{\text {tabel }}$ maka hipotesis alternative (Ha) diterima dan hipotesis nol (Ho) ditolak

ii. Jika $t_{\text {hitung }}<t_{\text {tabel }}$ maka hipotesis alternative (Ha) ditolak dan hipotesis nol (Ho) diterima ${ }^{22}$

Dilihat bahwa data Pretest normal dengan $T_{\text {hitung }}=0,408<1,70=T_{\text {tabel }}$, artinya Ho diterima sedangkan data Posttest normal dengan $T_{\text {hitung }}=3,84>1,70=T_{\text {tabel }}$. Data hasil analisis Gain normal dengan dengan $T_{\text {hitung }}=4,36>1,70=T_{\text {tabel }}$

\footnotetext{
${ }^{19}$ Subana, dkk. Statistik Pendidikan, 171.

${ }^{20}$ Subana, dkk. Statistik Pendidikan, 171.

${ }^{21}$ Subana, dkk. Statistik Pendidikan, 172.

${ }^{22}$ Subana, dkk. Statistik Pendidikan, 173.
} 
Kriteria pengujian dengan menggunakan taraf kesalahan 0,05 (5\%), maka pretest harga $\mathrm{T}$ tabelnya ialah 1,70. Pengujian dengan kriteria hipotesis jika $T_{\text {hitung }}>T_{\text {tabel }}$, maka Ho diterima, tidak ada perbedaan pemahaman awal siswa pada kedua kelas tersebut yang berarti pemahaman awal kelas sama. Dengan kata lain bahwa antara kelas VIII A dan kelas VIII B tidak ada perbedaan yang signifikan mengenai pengetahuan awal mereka. Maka peneliti senantiasa memilih kelas VIII A sebagai kelas kontrol dan kelas VIII B sebagai kelas eksperimen.

Sedangkan data Posttest harga $\mathrm{T}$ tabelnya ialah 1,70. Pengujian dengan kriteria hipotesis jika $T_{\text {hitung }}>T_{\text {tabel }}$ maka Ho ditolak dan Ha diterima. Berdasarkan perhitungan diperoleh $T_{\text {hitung }}=3,84>1,70=T_{\text {tabel }}$, maka Ho ditolak dan Ha diterima, maka metode small group work dan media audio visual powerpoint dan metode pembelajaran konvensional berpengaruh terhadap belajar kognitif siswa pada mata pelajaran Al-Qur'an Hadits bab Hukum lam jalalah dan ra'.

Tabel 10

Hasil Efek Perlakuan

\begin{tabular}{|l|c|c|c|c|}
\hline $\begin{array}{c}\text { Kelompok } \\
\text { (Group) }\end{array}$ & $\begin{array}{c}\text { Test Awal } \\
\text { (Pre-test) }\end{array}$ & $\begin{array}{c}\text { Perlakuan } \\
\text { (Treatment) }\end{array}$ & $\begin{array}{c}\text { Test Akhir } \\
\text { (Post-test) }\end{array}$ & Gain \\
\hline Eksperimen & 42,87 & $X_{1}$ & 83 & 40,37 \\
\hline Kontrol & 41,56 & $X_{2}$ & 70,25 & 30,12 \\
\hline \multicolumn{2}{|l|}{ Efek Perlakuan $:\left(O_{2}-O_{1}\right)-\left(O_{4}-O_{3}\right)$} & 10,25 \\
\hline
\end{tabular}

Setelah melakukan penelitian ini diperoleh data perbedaan hasil belajar kognitif siswa antara yang menggunakan metode small group work dan media audio visual powerpoint dan yang menggunakan metode pembelajaran konvensional. Hal ini terbukti hasil belajar dengan menggunakan metode small group work dan media audio visual powerpoint 83. Ini menunjukkan bahwa rata-rata hasil belajar yang menggunakan metode small group work dan media audio visual powerpoint dalam kategori baik. Sedangkan kelas yang menggunakan metode pembelajaran konvensional diperoleh hasil belajar sebesar 70,25. Ini menunjukkan bahwa rata-rata hasil belajar yang menggunakan metode pembelajaran konvensional dalam kategori cukup.

Keberhasilan atau kegagalan guru dalam menjalankan proses belajar mengajar banyak ditentukan oleh kecakapannya dalam memilih dan menggunakan metode mengajar. Seringkali dijumpai seorang guru memiliki pengetahuan luas terhadap materi yang diajarkan, namun tidak berhasil dalam mengajar. Salah satu faktor penyebabnya adalah kurangnya penguasaan metode mengajar. Disinilah, terlihat betapa pentingnya metode mengajar bagi 
seorang guru. Oleh karenanya, penguasaan terhadap metode pengajaran menjadi salah satu prasyarat dalam menentukan keberhasilan seorang guru.

Untuk menghasilkan proses pembelajaran yang berkualitas dan hasil belajar yang maksimal maka tidak cukup hanya dengan memilih metode yang sesuai dengan materi pelajaran saja, tetapi juga perlu dibarengi dengan penggunaan media pembelajaran. Media dalam aktivitas pembelajaran merupakan sesuatu yang dapat membawa informasi dan pengetahuan dalam interaksi yang berlangsung antara guru dan siswa. Penggunan media pembelajaran berfungsi sebagai alat bantu mengajar, yakni menunjang penggunaan metode mengajar yang dipergunakan guru. ${ }^{23}$ Salah satu media yang dapat menunjang penggunaan metode mengajar adalah media audio visual powerpoint. Microsoft PowerPoint merupakan program aplikasi presentasi dalam komputer. Sebagai program aplikasi presentasi yang populer, Microsoft PowerPoint paling banyak digunakan untuk berbagai kepentingan presentasi, baik presentasi produk, meeting, seminar, lokakarya, dan dalam pembelajaran. ${ }^{24}$

Berbeda dengan penyelenggaraan pembelajaran konvensional merupakan sebuah pembelajaran yang lebih menekankan pada pemberian informasi dari guru kepada siswa. Sumber pembelajaran konvensional lebih banyak bersifat tekstual daripada kontekstual. Sumber informasi dipandang sangat mempengaruhi proses belajar. Pembelajaran konvensional lebih terpusat pada guru, karena guru lebih mendominasi kegiatan pembelajaran.

Putrayasa (2009) mengatakan bahwa pembelajaran konvensional ditandai dengan penyajian pengalaman-pengalaman yang berkaitan dengan konsep yang akan dipelajari, dilanjutkan dengan pemberian informasi oleh guru, tanya jawab, pemberian tugas oleh guru, pelaksanaan tugas oleh siswa sampai pada akhirnya guru merasa bahwa apa yang telah diajarkan dapat dimengerti oleh siswa. Meski metode ini lebih banyak menuntut keaktifan guru dari pada anak didik, tetapi metode ini tetap tidak bisa ditinggalkan begitu saja dalam kegiatan pengajaran. ${ }^{25}$

Pembelajaran konvensional masih dilaksanakan atas asumsi bahwa suatu pengetahuan dapat dipindahkan secara utuh dari pikiran guru ke siswa. Metode pengajaran secara konvensional selama ini lebih ditekankan pada tugas guru untuk memberikan intruksi atau ceramah selama proses pembelajaran berlangsung, sementara itu siswa hanya menerima pembelajaran secara pasif.

\footnotetext{
${ }^{23}$ Sudjana dan Rivai, Media Pengajaran, (Bandung: Sinar Baru Algensindo, 2010), 7.

${ }^{24}$ Asyhar, Kreatif Mengembangkan Media Pembelajaran, (Jakarta: Referensi Jakarta, 2012), 185.

${ }^{25}$ Djamarah, Bahri, dan Zain. Strategi Belajar Mengajar (Jakarta: Rineka Cipta, 2010), 97.
} 
Jadi dengan ini dapat dikatakan bahwa hasil belajar kognitif siswa antara yang menggunakan metode small group work dan media audio visual powerpoint lebih baik dengan yang menggunakan metode pembelajaran konvensional.

\section{KESIMPULAN}

Berdasarkan nilai rata-rata posttest pada kelas kontrol sebesar 70,25 dan kelas eksperimen sebesar 83, maka hal tersebut menunjukkan adanya perbedaan hasil belajar kognitif siswa dengan selisih 10,25. Hal ini dapat dilihat pula dari hasil uji tes $t$ data posttest dan uji tes $t$ nilai gain kedua kelas tersebut, yaitu kelas yang pembelajarannya menggunakan metode konvensional dengan kelas yang pembelajarannya menggunakan metode small group work dan media audio visual powerpoint diperoleh bahwa $t_{\text {hitung }}>t_{\text {tabel }}=3,84>1,70$ maka Ho ditolak dan Ha diterima, yang berarti terdapat perbedaan hasil belajar kognitif antara kelas eksperiment dengan kelas kontrol. Sedangkan hasil uji tes $t$ untuk nilai gain diperoleh bahwa bahwa $t_{\text {hitung }}>\mathrm{t}_{\text {tabel }}=4,36>1,70$ maka Ho ditolak dan Ha diterima, yang berarti terdapat perbedaan gain antara kelas eksperimen dan kelas kontrol. Dengan kata lain hasil belajar kognitif siswa pada bab materi hukum lam jalalah dan ra' yang pembelajarannya menggunakan metode small group work dan media audio visual powerpoint lebih baik dibandingkan dengan yang menggunakan metode konvensional. Oleh karena itu, metode pembelajaran small group work dan media audio visual powerpoint berpengaruh terhadap hasil belajar kognitif siswa pada mata pelajaran al-Qur'an Hadits.

Setelah mengetahui hasil penelitian mengenai pengaruh penggunaan metode pembelajaran small group work dan media audio visual powerpoint terhadap hasil belajar kognitif siswa, maka terdapat beberapa saran sebagai berikut:

1. Metode small group work dan media audio visual powerpoint bisa digunakan sebagai alternatif metode dan media pada mata pelajaran PAI untuk meningkatkan hasil belajar kognitif siswa. Disarankan penggunaannya harus sesuai dengan meteri yang diajarkan.

2. Pendidik hendaknya lebih menunjukkan kreatifitasnya dalam mengajar dengan memanfaatkan media pembelajaran agar menghasilkan siswa yang kreatif pula.

3. Pendidik hendaknya lebih mampu menyesuaikan metode pembelajaran dengan materi pembelajaran agar siswa lebih memahami materi sehingga hasil belajarnya lebih maksimal.

\section{REFERENSI}


Sardiman, A.M. Interaksi dan Motivasi Belajar Mengajar. Jakarta: Raja Grafindo Persada, 2014.

Sutikno, Sobry. Belajar dan Pembelajaran. Bandung: Prospect, 2008.

Susilana, Rudi dan Cepi Riyana. Media Pembelajaran. Bandung: CV Wacana Prima, 2007.

Munadi, Yudhi. Media Pembelajaran. Jakarta: GP Press, 2008.

Sugiyono. Metode Penelitian Kuantitatif, Kualitatif dan Kombinasi. Bandung: Alfabeta, 2015.

Sugiyono. Statistika Untuk Penelitian. Bandung: Alfabeta, 2015.

Subana, dkk. Statistik Pendidikan. Bandung: Pustaka Setia, 2000.

Hayati, Tuti. Modul Evaluasi Pembelajaran PAI, Bandung: Fakultas Tarbiyah UIN, 2012.

Sudjana, Nana dan Ahmad Rivai. Media Pengajaran. Bandung: Sinar Baru Algensindo, 2009.

Asyhar, Rayanda. Kreatif Mengembangkan Media Pembelajaran. Jakarta: Referensi Jakarta, 2012

Djamarah, Syaiful Bahri dan Aswan Zain. Strategi Belajar Mengajar. Jakarta: Rineka Cipta, 2010. 